\title{
Genetic structure of the shrub Daphne laureola across the Baetic Ranges, a Mediterranean glacial refugium and biodiversity hotspot
}

\author{
A. R. Castilla, C. Alonso \& C. M. Herrera \\ Estación Biológica de Doñana, Consejo Superior de Investigaciones Científicas (CSIC), Sevilla, Spain
}

Keywords

Daphne laureola; genetic differentiation; genetic diversity; neutral genetic

differentiation; population size; spatial

isolation.

\section{Correspondence}

A. R. Castilla, Estación Biológica de Doñana, Consejo Superior de Investigaciones

Científicas (CSIC), Avenida Américo Vespucio $\mathrm{s} / \mathrm{n}, \mathrm{E}-41092$ Sevilla, Spain.

E-mail: acastilla@ebd.csic.es

\begin{abstract}
Distribution margins constitute areas particularly prone to random and/or adaptive intraspecific differentiation in plants. This trend may be particularly marked in species discontinuously distributed across mountain ranges, where sharp geographic isolation gradients and habitat boundaries will enhance genetic isolation among populations. In this study, we analysed the level of neutral genetic differentiation among populations of the long-lived shrub Daphne laureola (Thymelaeaceae) across the Baetic Ranges, a glacial refugium and biodiversity hotspot in the western Mediterranean Basin. Within this area, core and marginal populations of D. laureola were compared with regard to their spatial isolation, size, genetic diversity and differentiation. A spatially explicit analysis conducted on the vast majority of the species' known populations in the study area $(\mathrm{N}=111)$ showed that marginal populations (western and eastern) present larger spatial isolation than core populations, but are not smaller. We compared genetic diversity and differentiation between core and marginal populations using a subsample of 15 populations and 225 amplified fragment length polymorphism (AFLP) markers. Core and marginal populations did not differ in genetic diversity, probably because of the occurrence of large populations on the local margins. Western populations were strongly differentiated from the other populations. In addition, spatial and genetic differentiation among populations was larger on the western margin. Eastern populations constituted a genetically homogeneous group closely related to core populations, despite their greater spatial isolation. Results suggest that studies on phenotypic differentiation between core and marginal populations of D. laureola, and presumably other species having discontinuous distributions across the Baetic ranges, should take into account geographical differences in levels of genetic differentiation between the different distribution borders.
\end{abstract}

\section{INTRODUCTION}

High mountains are continental islands from a biogeographic perspective, each one surrounded by low-altitude environments characterised by unsuitable present-day climatic conditions for cold-adapted mountain plants (although see Birks \& Willis 2008). Consequently, many mountain plants often show disjunct geographic distributions. Within each distribution patch, the species colonises a geographic gradient of environmental conditions and becomes more abundant where individual survival, reproduction and hence population growth are highest, and increasingly less abundant as conditions depart from this optimum (Hengeveld \& Haeck 1982; Brown 1984). Therefore, within each distribution patch, a species is expected to exhibit a local centre of abundance or core region, with populations becoming progressively smaller and more spatially isolated towards the local range limits (Brussard 1984; Vucetich \& Waite 2003). Such a combination of geographic variation in population size and spatial isola- tion is expected to have important consequences for the genetic structure of plant populations (Vucetich \& Waite 2003; Alleaume-Benharira et al. 2006). Genetic models of ecological margins pertain to local range margins rather than species global distribution margins because they consider a continuous spatial area that is not much larger than the dispersal distance (Alleaume-Benharira et al. 2006; Bridle \& Vines 2007; Bridle et al. 2010). These genetic models predict, within an ecological gradient, (i) reduced genetic diversity of marginal populations because of founder effects, bottlenecks, inbreeding, genetic drift or directional selection; and (ii) increased genetic differentiation among marginal populations through reduced gene flow (Young et al. 1996; Lammi et al. 1999; Lowe et al. 2005). Furthermore, marginal and isolated populations could be genetically distinct as a result of reduced arrival of maladapted genes from core populations ('gene swamping'; García-Ramos \& Kirkpatrick 1997; Alleaume-Benharira et al. 2006), favouring adaptation to local environments and thus becoming particularly valuable for 
species maintenance at the global scale (Lesica \& Allendorf 1995). Therefore, determining the level of spatial and genetic isolation of marginal populations with regard to core populations, as well as genetic diversity within populations, genetic differentiation among populations and its relationship with spatial isolation is necessary to evaluate the distinctiveness and adaptive potential of marginal populations, particularly in plants associated with mountainous environments.

Recently Eckert et al. (2008) reviewed 84 studies involving 67 plant species that tested for declines in within-population genetic diversity and/or increases in among-population differentiation towards range margins using nuclear molecular genetic markers. They found that $64.2 \%$ and $70.3 \%$ of studies detected a decline of genetic diversity and an increase of genetic differentiation towards range margins, respectively, the two trends being positively associated. However, the generality of both trends is questionable given the substantial biogeographic and taxonomic biases in the available studies. First, most studies assume that marginal populations are smaller and more spatially isolated than core populations, although only a few investigations have quantified the spatial isolation of populations and its relationship with genetic differentiation (but see Eckstein et al. 2006; Medrano \& Herrera 2008). Furthermore, most studies have focused on northern borders of a species yet different selective pressures could operate in contracting versus expanding margins (Hampe \& Petit 2005; Cassel-Lundhagen 2010). For most temperate woody species, the Mediterranean mountains constitute the southernmost distribution limit. These areas, in contrast to northernmost expanding distribution limits, represent longterm stable margins that have acted as glacial refugia during the last glacial stage (Bennett et al. 1991; Carrión 2002; Carrión et al. 2003; Médail \& Diadema 2009). However, the number of molecular analyses of plant populations in these areas is still limited compared with more northern European mountain ranges such as the Alps, Pyrenees or Carpathians (Kropf et al. 2008; but see Kropf et al. 2006; Herrera \& Bazaga 2008a,b; Medrano \& Herrera 2008). In addition, Mediterranean mountains constitute one of the world biodiversity hotspots because of their high complexity in terms of geology, climate and history (Thompson 2005; Blondel et al. 2010). Therefore, analysing the current genetic structure of plant populations in Mediterranean mountains may be useful to understand how the orography of heterogeneous landscapes contributes to genetic isolation of populations promoting intraspecific differentiation (Thompson 2005: 77-80; Médail \& Diadema 2009).

In this study, we tested for differences in population size, spatial isolation and genetic diversity and differentiation of marginal and core populations of the temperate evergreen shrub Daphne laureola in the Baetic Ranges, a glacial refugium and one of the most biologically diverse regions in the Mediterranean Basin, located in the southern Iberian Peninsula. This area constitutes the southernmost distribution patch of the species in Europe, encompassing $>100$ populations with a maximum distance among them ca. $350 \mathrm{~km}$, and largely isolated from other distribution patches (Alonso et al. 2007). Specifically, we addressed the following questions: (i) Are marginal populations smaller and more spatially isolated than core populations? (ii) Do core populations have larger genetic diversity than marginal ones? (iii) Are marginal popu- lations more genetically differentiated than core populations? (iv) Do marginal populations form distinct genetic groups to core populations at this southern distribution patch?

\section{MATERIALS AND METHODS}

\section{Study species}

Daphne laureola L. (Thymelaeaceae) has a Palaearctic distribution, extending from the Atlas Mountains in Morocco to the UK and Hungary northwards (Meusel et al. 1978; Fig. 1 a). The species grows in the understorey of coniferous and mixed forests, associated with the main calcareous ranges of Europe and North Africa. In the Iberian Peninsula, it shows a disjunct distribution, being abundant in the northern Cantabrian Range and the Pyrenees, and also in the southern Baetic Ranges, but absent in central areas (Alonso et al. 2007 and references therein).

The species flowers in winter, and the pollen beetle Meligethes elongatus Rosenhauer and, to a much lesser extent, small solitary bees and noctuid moths are its main pollinators in southeast Spanish populations (Alonso 2004). However, a recent study has shown that $M$. elongatus does not visit D. laureola flowers in populations on the southwest edge (Castilla et al. 2011). Single-seeded black drupes ripen in June and are dispersed by several bird species (Obeso 1985; Hulme 1992).

Spatial isolation and size of D. laureola populations in a southern distribution patch

A heterogeneous spatial distribution of D. laureola populations in the study area was evident a priori, with a few isolated and scattered populations located in the west, and a large cluster of core populations that become progressively sparser towards the east (Fig. $1 \mathrm{~b}$ and c). For this study, we located 111 populations of D. laureola across the Baetic Ranges through an extensive search over several years (Fig. 1 b). The wide network of roads and tracks across these mountain ranges allowed a thorough exploration of the study region. We feel confident that the vast majority of populations of the species in the study region were included and the presence of D. laureola populations in other massifs could not be confirmed, despite intensive searches.

We considered a population as a discrete group of individuals distant from other groups of individuals by at least $1 \mathrm{~km}$. Each population was visited at flowering season. Population size was categorised according to the abundance of reproductive individuals: (i) $£ 30$ (small populations), (ii) 31-99 (intermediate populations) and (iii) $\ddagger 100$ (large populations). The geographic coordinates were recorded with a portable GPS GARMIN eTrex Vista (GARMIN, Southampton, UK) in each population. Spatial isolation of populations was quantified through a connectivity index per population (connectivity, hereafter). Connectivity of a given population i was described by a simple neighbourhood index $\mathrm{C}_{\mathrm{i}}(\mathrm{r})$ computed as the number of further populations within a given distance $r$ of the focal population i. We used a distance $r$ of $25 \mathrm{~km}$ that potentially covers the maximum travel distance of $\mathrm{D}$. laureola's pollinators and seed dispersers. Note that this index is proportional to the individual K-function of population i, e.g., $\mathrm{C}_{\mathrm{i}}(\mathrm{r})=\mathrm{k} \mathrm{K}_{\mathrm{i}}(\mathrm{r})$, where $\mathrm{k}$ is the density of populations in the 

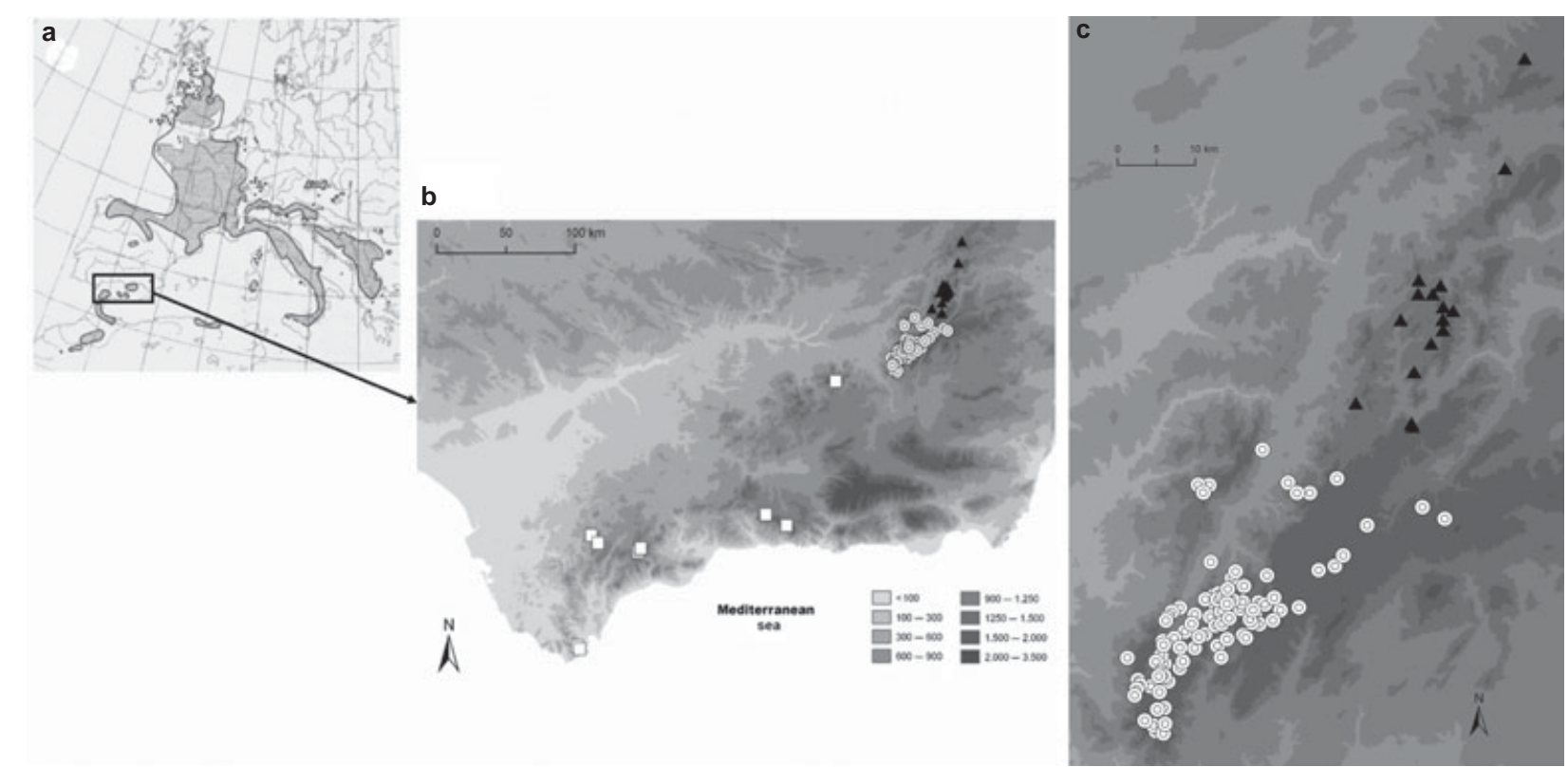

Fig. 1. a: Global distribution range of Daphne laureola indicated with grey shading. b: Distribution of D. laureola populations in the Baetic Ranges (southern Spain), and location of the eastern, core and western regions defined in this study, here denoted by black triangles, filled circles and white squares, respectively. The grey scale corresponds to different intervals of altitude in the region (m.a.s.l.). c: Detailed map encompassing core and eastern populations of D. laureola in the study area (filled circles and black triangles, respectively).

study area (Illian et al. 2008: 256). The common K-function (Ripley 1981) is the average value of the individual K-function taken over all populations.

\section{Genetic structure of representative populations}

For the purpose of determining the genetic structure of populations in this southern distribution patch, we chose a subsample of 15 populations representing the three regions within the study area (eastern, core and western). We intensively studied the genetic characteristics of five populations per region (Table 1) through analysis of amplified fragment length polymorphism (AFLP) markers. Distances between the two closest (CDE-VCV) and farthest (NVL-ALG) populations studied were 1.7 and $360 \mathrm{~km}$, respectively. In each population we counted all reproductive individuals to obtain a more precise estimate of population size (Table 1). Fresh leaf material was collected from 25-40 reproductive individuals per population chosen randomly, placed in small paper envelopes and dried immediately at ambient temperature in sealed containers with abundant silica gel. Dried leaves were homogenised to a fine powder using a Retsch MM 200 mill (Restch, Haan, Germany). Total genomic DNA was extracted from approximately $15 \mathrm{mg}$ of ground leaf material using the DNeasy Plant Mini kit (Qiagen, Hilden, Germany) and following the manufacturer's protocol. DNA concentration of extracts was estimated by running electrophoreses of 5-11 aliquots on $0.8 \%$ agarose gels. The AFLP analysis was performed essentially as originally described in Vos et al. (1995), with modifications involving the use of fluorescent dyelabelled selective primers following Applied Biosystems (2005) instructions. Restriction-ligation was conducted using EcoRI/MseI and PstI/MseI endonuclease mixtures and doubled-stranded adaptors. A total of 32 EcoRI +3 MseI +3 and
32 PstI +3 MseI +3 primer pairs were first screened for selective amplification in a pilot study conducted with a random subsample of eight individuals from four widely scattered populations. We finally selected four EcoRI $+3 / \mathrm{M}$ seI +3 and four PstI/MseI +3 primer combinations because of their larger polymorphism and easier interpretable band patterns (Supporting Information).

Each plant was fingerprinted using the eight combinations chosen. Fragment separation and detection was made using an ABI PRISM 3130 - 1 DNA sequencer (Applied Biosystems, Foster City, CA, USA). The presence or absence of each marker in each individual plant was scored manually by visualising electrophoregrams with GeneMapper 3.7 software (Applied Biosystems). All scoring was done by the same person (A.R.C.). Prior to statistical analyses, we excluded markers present in $<1$ or $>99 \%$ of individuals $(\mathrm{N}=100)$. Furthermore, only fragments $¥ 150$ bp in size were considered, as a way of reducing the potential impact of size homoplasy (Vekemans et al. 2002; Caballero et al. 2008). In addition, five plants that produced noisy sequencer electrophoregrams for some primer combinations, after running the analyses several times, were also excluded from the sample. The combination of 225 polymorphic markers, each one scored for presence/absence, and 25-40 individuals per population $(\mathrm{N}=533)$ used in this study was sufficient to produce reasonably narrow standard errors and adequate statistical power to detect genetic differentiation among populations (Medina et al. 2006; Bonin et al. 2007).

Genotyping error rates were determined for each primer combination by running repeated, independent analyses for a total of 32 randomly chosen individual plants, and estimated as the ratio of the total number of loci with discordant scores (all individuals combined) to a product of the number of individuals by the total number of scored loci (Bonin et al. 
Table 1. Population features and genetic diversity of Daphne laureola populations studied in the three defined regions.

\begin{tabular}{|c|c|c|c|c|c|c|c|c|}
\hline population (code) & altitude (m.a.s.l.) & population size & connectivity & $\mathrm{N}$ & $\mathrm{H}_{\mathrm{j}}$ & PLP & private bands & DW \\
\hline \multicolumn{9}{|l|}{ eastern } \\
\hline Acebeas (ACB) & 1320 & 1436 & 14 & 35 & $0.130 \pm 0.011$ & 32.4 & 0 & 0.38 \\
\hline Acebeas de los Jabalises (ACJ) & 1430 & 354 & 22 & 42 & $0.126 \pm 0.010$ & 34.2 & 0 & 0.37 \\
\hline Las Cumbres (CUM) & 1480 & 56 & 29 & 30 & $0.135 \pm 0.011$ & 32.9 & 0 & 0.45 \\
\hline Navalasna (NVL) & 1202 & 55 & 14 & 38 & $0.105 \pm 0.010$ & 26.7 & 1 & 0.40 \\
\hline \multirow[t]{2}{*}{ Río Madera (RMD) } & 1220 & 932 & 17 & 30 & $0.133 \pm 0.011$ & 33.8 & 2 & 0.47 \\
\hline & & & & & $0.126 \pm 0.005$ & 32.0 & 0.6 & 0.41 \\
\hline \multicolumn{9}{|l|}{ core } \\
\hline Cañada del Espino (CDE) & 1575 & 178 & 89 & 40 & $0.113 \pm 0.011$ & 27.6 & 0 & 0.35 \\
\hline Espinarea (ESP) & 1173 & 86 & 81 & 29 & $0.119 \pm 0.010$ & 29.3 & 0 & 0.44 \\
\hline Fuente Bermejo (FBJ) & 1513 & 2115 & 89 & 40 & $0.158 \pm 0.011$ & 40.0 & 1 & 0.49 \\
\hline Roblehondo (RBH) & 1235 & 55 & 89 & 26 & $0.125 \pm 0.011$ & 27.1 & 0 & 0.40 \\
\hline \multirow[t]{2}{*}{ Valdecuevas (VCV) } & 1380 & 2787 & 89 & 39 & $0.185 \pm 0.012$ & 45.3 & 0 & 0.42 \\
\hline & & & & & $0.140 \pm 0.014$ & 33.9 & 0.2 & 0.42 \\
\hline \multicolumn{9}{|l|}{ western } \\
\hline Almijara (ALM) & 1453 & 1000 & 1 & 31 & $0.068 \pm 0.009$ & 13.3 & 0 & 0.62 \\
\hline Algeciras (ALG) & 506 & 100 & 1 & 39 & $0.080 \pm 0.010$ & 19.1 & 4 & 0.61 \\
\hline Fuente Molina (FML) & 1380 & 621 & 2 & 46 & $0.195 \pm 0.012$ & 48.9 & 1 & 0.68 \\
\hline Grazalema (GRZ) & 1229 & 1580 & 2 & 46 & $0.100 \pm 0.010$ & 27.6 & 2 & 0.46 \\
\hline \multirow[t]{2}{*}{ Sierra del Reloj (SRJ) } & 1126 & 28 & 2 & 22 & $0.124 \pm 0.011$ & 24.4 & 3 & 0.68 \\
\hline & & & & & $0.113 \pm 0.022$ & 26.7 & 2 & 0.61 \\
\hline
\end{tabular}

Population size refers to total number of individuals per population; connectivity refers to the number of neighbour populations in a radius of $25 \mathrm{~km}$ (see text for details).

$\mathrm{N}=$ number of plants used in genetic analyses; $\mathrm{H}_{\mathrm{j}}=$ within-population gene diversity; PLP = percentage of polymorphic loci (out of a total of 225 loci scored); DW = within-population rarity of markers (see text for details).

2004; Pompanon et al. 2005). Error rates varied among primer combinations, being larger in individual EcoRI combinations than in PstI combinations (Supporting Information). The mean value $( \pm \mathrm{SE})$ for the whole set of eight combinations was $0.9 \pm 0.4 \%$.

\section{Data analyses}

Size and spatial isolation of populations

Unless otherwise stated, all statistical analyses were conducted with sas 9.1 (SAS Institute 2002). Differences between regions in connectivity were tested using a generalised linear model including connectivity as dependent variable and region as the only fixed explanatory factor (Procedure GENMOD). Connectivity was modelled using the Poisson distribution. Population size was analysed with the Kruskal-Wallis test, considering population size categories as ranks of population size and region as categorical explanatory variable. To test for regional differences in connectivity and population size, we explored differences between core versus marginal populations using post hoc Wilcoxon tests.

\section{Genetic structure}

Gene diversity $(\mathrm{Hj})$, percentage of polymorphic loci (i.e., loci with allelic frequencies within the range 0.05-0.95; PLP hereafter) and population pair-wise $\mathrm{F}_{\mathrm{ST}}$ values were calculated with AFLPsurv 1.0 (Vekemans et al. 2002), computing allelic frequencies with a Bayesian method with non-uniform prior distribution and 10,000 permutations. These parameters were estimated assuming both Hardy-Weinberg equilibrium $\left(F_{\text {is }}=0\right)$ and complete selfing $\left(F_{i s}=1\right)$, with very little effect on the results that did not change the general conclusions. Additionally, the Rarity 1 index (equivalent to the frequency of down-weighted marker values; i.e., DW sensu Schönswetter \& Tribsch 2005) was calculated using AFLPdat (Ehrich 2006). Group-based DW estimates were obtained by non-parametric bootstrapping of plant individual values (not population averages) for each population. The number of private bands was also calculated using GenAlEx 6.3 (Peakall \& Smouse 2006). The significance of differences between core and marginal populations in genetic diversity and differentiation was tested using non-parametric methods (procedure NPAR1WAY). Gene diversity, PLP and DW presented normal distributions, however, we used Wilcoxon exact tests to analyse them because of the reduced sample size in the paired tests $(\mathrm{N}=10)$. Population $\mathrm{F}_{\mathrm{ST}}$ was calculated averaging the $\mathrm{F}_{\mathrm{ST}}$ values of each population with all other four populations within the same region. This variable was not normally distributed; consequently, the differences between core and marginal populations were also explored with Wilcoxon exact tests. The influence of population size and connectivity on genetic diversity (PLP and $\mathrm{Hj}$ ) and differentiation (DW and $\mathrm{F}_{\mathrm{ST}}$ ) was analysed using Spearman correlations.

A three-level hierarchical analysis of molecular variance (amova; Excoffier et al. 1992) was calculated with the program GenAlEx 6.3. We analysed the following levels: (i) region (eastern, core and western); (ii) populations within region; and (iii) individuals within populations. Additionally, separate twolevel amovas were calculated for each region to analyse the partitioning of molecular variance among and within populations. A standard test for genetic isolation by geographic distance was ruled out for two reasons. On the one hand, the low 
number of populations per region $(\mathrm{N}=5)$ did not allow testing for genetic isolation by distance in each region. On the other hand, western populations were so distant from the remaining populations $(>138 \mathrm{~km})$ that it introduces a large discontinuity better described by the categorical variable 'region' than by the continuous variable 'geographic distance'.

Relationships among populations were visualised through neighbour-joining clustering of pair-wise $\mathrm{F}_{\mathrm{ST}}$, and the significance of the branches was assessed through 10,000 bootstrap replicates (Felsenstein 1985). A second approach based on statistical inference with Bayesian clustering methods using structure 2.2.3 (available online: http://pritch.bsd.uchicago. edu/structure_software/release_versions/v2.3.3/html/structure. html) was also used to further elucidate the uppermost level of genetic structure in the study region (Pritchard et al. 2000; Falush et al. 2007). This program probabilistically assigns genotyped individuals into genetic groups in order to minimise departures from Hardy-Weinberg equilibrium and linkage equilibrium. The number of genetic groups was explored by performing 20 replicates of each simulation from $\mathrm{K}=1$ to $\mathrm{K}=17$, with a burn-in of 50,000 and MCMC of 100,000, assuming admixture and correlated allele frequencies, as recommended in Pritchard et al. (2000). We applied Evanno et al. (2005) modal DK parameter as the choice criterion to detect the true number of genetic groups in the set of $\mathrm{N}=533$ individuals assayed.

\section{RESULTS}

Are marginal populations more spatially isolated and smaller than core populations?

We found differences between regions in connectivity $\left(\mathrm{v}^{2}=1745.08, \mathrm{df}=2, \mathrm{P}<0.0001\right.$; Kruskal-Wallis test $)$, with density of neighbour populations being largest in the core region (Table 2). Core populations had more than four times the number of neighbour populations within $25 \mathrm{~km}$ than eastern populations ( $\mathrm{W}=43.29, \mathrm{P}<0.0001$; Table 2$)$. The difference with western populations was even larger. Core populations had more than 80 times the number of populations within $25 \mathrm{~km}$ than western populations ( $\mathrm{W}=17.20$, $\mathrm{P}<0.0001$; Table 2).

There was a significant difference in population size among regions $\left(\mathrm{v}^{2}=8.52, \mathrm{df}=2, \mathrm{P}<0.05\right.$; Kruskal-Wallis test $)$. Unexpectedly, the core region had the lowest population sizes, with only $17 \%$ of populations having more than 100

Table 2. Average values of connectivity in eastern, central and western populations of $\mathrm{D}$. laureola in the south of the Iberian Peninsula.

\begin{tabular}{llllll}
\hline & & & \multicolumn{3}{l}{$\begin{array}{l}\text { population size } \\
\text { category (\%) }\end{array}$} \\
& $N$ & connectivity & 1 & 2 & 3 \\
\hline eastern & 17 & $20.8 \pm 2.5$ & 12 & 47 & 41 \\
central & 88 & $82.6 \pm 0.8$ & 8 & 75 & 17 \\
western & 6 & $1.7 \pm 0.2$ & 17 & 0 & 83 \\
\hline
\end{tabular}

$\mathrm{N}$ indicates the number of populations in each region. Connectivity refers to the number of neighbour populations within a distance radius of $25 \mathrm{~km}$. Population size was categorised according to the abundance of reproductive individuals ((1) £30; (2) 31-100; (3) $¥ 100)$. The table shows the percentage of populations of each category per region. reproductive individuals, whereas the more isolated populations in the western region had the largest average size, with $83 \%$ of populations having more than 100 reproductive individuals (Table 2). Eastern and core populations did not differ in population size $(\mathrm{W}=605.5, \mathrm{P}=0.12)$ but western populations had larger average population size than core populations ( $\mathrm{W}=122, \mathrm{P}<0.01)$. Connectivity was not correlated with population size $\left.\left(\mathrm{r}_{\mathrm{s}}=\right) 0.15, \mathrm{P}=0.11 ; \mathrm{N}=111\right)$.

Do core populations have larger genetic diversity than marginal ones?

Average gene diversity of core populations did not differ significantly from eastern ( $\mathrm{W}=27$, $\mathrm{df}=8, \mathrm{P}=0.5$ ) or western populations $(\mathrm{W}=33$, $\mathrm{df}=8, \mathrm{P}=0.1)$, although mean $\mathrm{H}_{\mathrm{j}}$ tended to be slightly larger in core $(0.140)$ than in marginal populations ( 0.126 and 0.113 in eastern and western populations, respectively; Table 1). Western populations exhibited the broadest range of variation of gene diversity, presenting the minimum and maximum values (0.068 and 0.195$)$ of all studied populations. Similarly, core populations did not show statistically significant differences in the percentage of polymorphic loci (PLP) relative to eastern ( $\mathrm{W}=27, \mathrm{df}=8$, $\mathrm{P}=0.5$ ) or western populations $(\mathrm{W}=33.5$, $\mathrm{df}=8, \mathrm{P}=0.1$ ), although mean PLP tended to be larger in core than in marginal populations (33.9\%, 32.0\% and $26.7 \%$ in core, eastern and western populations, respectively; Table 1). Again, the maximum and minimum PLP values (48.9\% and $13.3 \%$ ) were found in western populations. The FML population had the largest average values of both gene diversity and PLP, in contrast to the rest of the western populations with low values for both estimates of genetic diversity. In fact, excluding FML from analysis led to an important decrease in genetic diversity of the western region $\left(\mathrm{H}_{\mathrm{j}}=0.093\right.$, PLP $\left.=21.1 \%\right)$. Population size and PLP showed a positive relationship, although it was only marginally significant $\left(\mathrm{r}_{\mathrm{s}}=0.50, \mathrm{P}=0.06\right.$, $\mathrm{N}=15$ ). No significant relationship was found between population size and gene diversity $\left(r_{s}=0.29, \quad P=0.30\right.$, $\mathrm{N}=15$ ). PLP and gene diversity were both positively related to connectivity, although the relationships were only marginally significant $\left(r_{\mathrm{s}}=0.47, \mathrm{P}=0.07, \mathrm{~N}=15\right.$ in both cases).

Are marginal populations more genetically differentiated than core populations?

On average, western populations had more private fragments (2.0) than either eastern or core populations (0.6 and 0.2 private fragments, respectively; Table 1 ). The westernmost population (ALG) had the highest number of private fragments, despite its low values for mean gene diversity and percentage of polymorphic loci (Table 1). Mean pair-wise $\mathrm{F}_{\mathrm{ST}}$ was larger in western than in core populations $(\mathrm{W}=55$, $\mathrm{df}=8$, $\mathrm{P}<0.0001$; Fig. 2), which were in turn more genetically differentiated than eastern ones $(\mathrm{W}=64$, $\mathrm{df}=8, \mathrm{P}<0.001$; Fig. 2). Furthermore, the genetic rarity index DW was significantly larger in western populations than in core populations $(\mathrm{W}=16$, $\mathrm{df}=8, \mathrm{P}<0.01$; Fig. 2$)$. In contrast, there were no differences in DW between core and eastern populations $(\mathrm{W}=26.5, \mathrm{df}=8, \mathrm{P}=0.4$; Fig. 2). Interestingly, genetic rarity was negatively related to connectivity $\left(r_{s}=\right) 0.59$, $\mathrm{P}<0.05, \quad \mathrm{~N}=15$ ). Population pair-wise $\mathrm{F}_{\mathrm{ST}}$ also was 


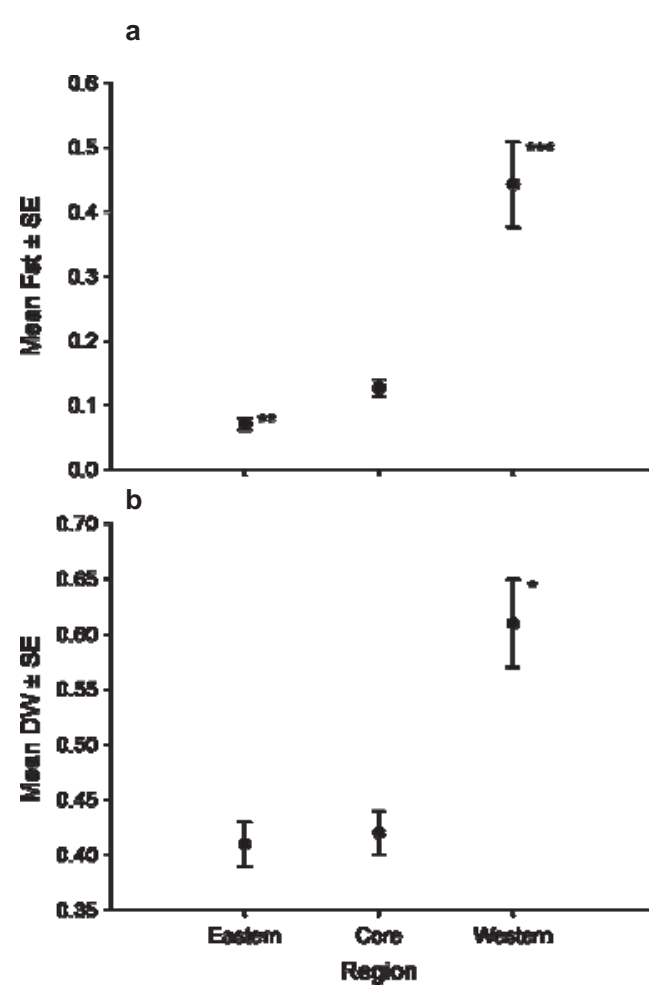

Fig. 2. Genetic differentiation of the populations in core and marginal regions. Population pair-wise $\mathrm{F}_{\mathrm{ST}}$ and genetic rarity (DW) per region (eastern, core and western) are represented as means $( \pm S E)$. Statistically significant variation between marginal and core populations is indicated with asterisks $\left({ }^{*} \mathrm{P}<0.01\right.$; ${ }^{* *} \mathrm{P}<0.001$; $\left.{ }^{* * *} \mathrm{P}<0.0001\right)$.

negatively related to connectivity of populations, although the relationship was only marginally significant $\left(r_{\mathrm{s}}=\right) 0.47$, $\mathrm{P}=0.08, \mathrm{~N}=15)$. Population size was unrelated to genetic rarity and population pair-wise $\mathrm{F}_{\mathrm{ST}}\left(\mathrm{r}_{\mathrm{S}}=0.03, \mathrm{P}=0.90\right.$ and $\mathrm{r}_{\mathrm{s}}=0.08, \mathrm{P}=0.79$, respectively; $\mathrm{N}=15$ ).

The three-level amova revealed a strong genetic differentiation among regions $\left(\mathrm{U}_{\mathrm{ST}}=0.45\right)$. Most molecular variance was accounted for by differences among regions and within populations (46\% and 40\%, respectively), whereas differences among populations within a region accounted for a reduced amount of molecular diversity (16\%). Results of the amova analysis also showed that western populations were more genetically differentiated among plants, with larger values of molecular variance explained among populations, and an average $U_{\mathrm{ST}}$ higher than eastern and core populations (Table 3). Eastern populations presented the lowest values of molecular variance explained among populations and $\mathrm{U}_{\mathrm{ST}}$ (Table 3).

Do marginal populations form genetically distinct groups?

Two distinct genetic clusters, one represented by the western populations and the other grouping together core and eastern populations, were supported by both neighbour-joining and Bayesian approaches (Figs 3 and 4). The dendrogram based on the neighbour-joining approach showed a split between western and the other populations with support of $100 \%$ (Fig. 3). Within the largest group, two populations, VCV and FBJ, both located in a particular watershed (Guadalentín Val-
Table 3. Genetic differentiation (UST) and percentage of molecular variance distributed among regions, among populations and within populations in the three regions defined in this study, 9999 permutations were used in the analysis.

\begin{tabular}{|c|c|c|c|c|}
\hline source of variation & df & $\%$ variance & $\mathrm{U}_{\mathrm{ST}}$ & P-value \\
\hline \multicolumn{5}{|l|}{ three-level AMOVA } \\
\hline among regions & 2 & 45 & 0.455 & 0.0001 \\
\hline among populations & 12 & 14 & & \\
\hline within populations & 518 & 40 & & \\
\hline \multicolumn{5}{|l|}{ eastern } \\
\hline among populations & 4 & 9 & 0.090 & 0.0001 \\
\hline within population & 170 & 91 & & \\
\hline \multicolumn{5}{|l|}{ core } \\
\hline among populations & 4 & 13 & 0.125 & 0.0001 \\
\hline within population & 169 & 87 & & \\
\hline \multicolumn{5}{|l|}{ western } \\
\hline among populations & 4 & 47 & 0.472 & 0.0001 \\
\hline within population & 179 & 53 & & \\
\hline
\end{tabular}

ley; Fig. 4b), appeared differentiated from each other and from the rest of the core and eastern populations, with support of $97 \%$ in both cases (Fig. 3). In addition, the Bayesian analysis showed a distinct modal maximum of $\mathrm{DK}$ at $\mathrm{K}=2$ genetic groups. Membership assignments to the two genetic groups exhibited a distinct geographic pattern coincident with the results of the neighbour-joining approach (Fig. 4a), supporting that western populations formed a genetic group differentiated from the rest of the populations analysed.

\section{DISCUSSION}

Genetic characteristics of populations may be strongly influenced by the size and spatial distribution of populations through their relationships in genetic drift and gene flow. Thus,

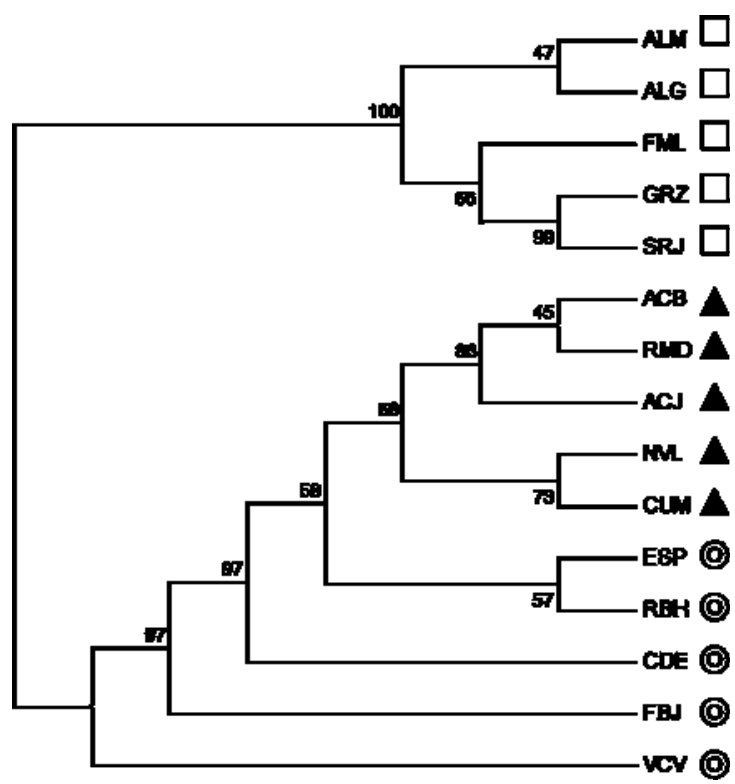

Fig. 3. Neighbour-joining clustering based on $F_{S T}$, showing relationships among the 15 sampled populations of D. laureola. Bootstrap percentage values are indicated above the branches. Populations coded as in Table 2 and regions as in Fig. 1. 


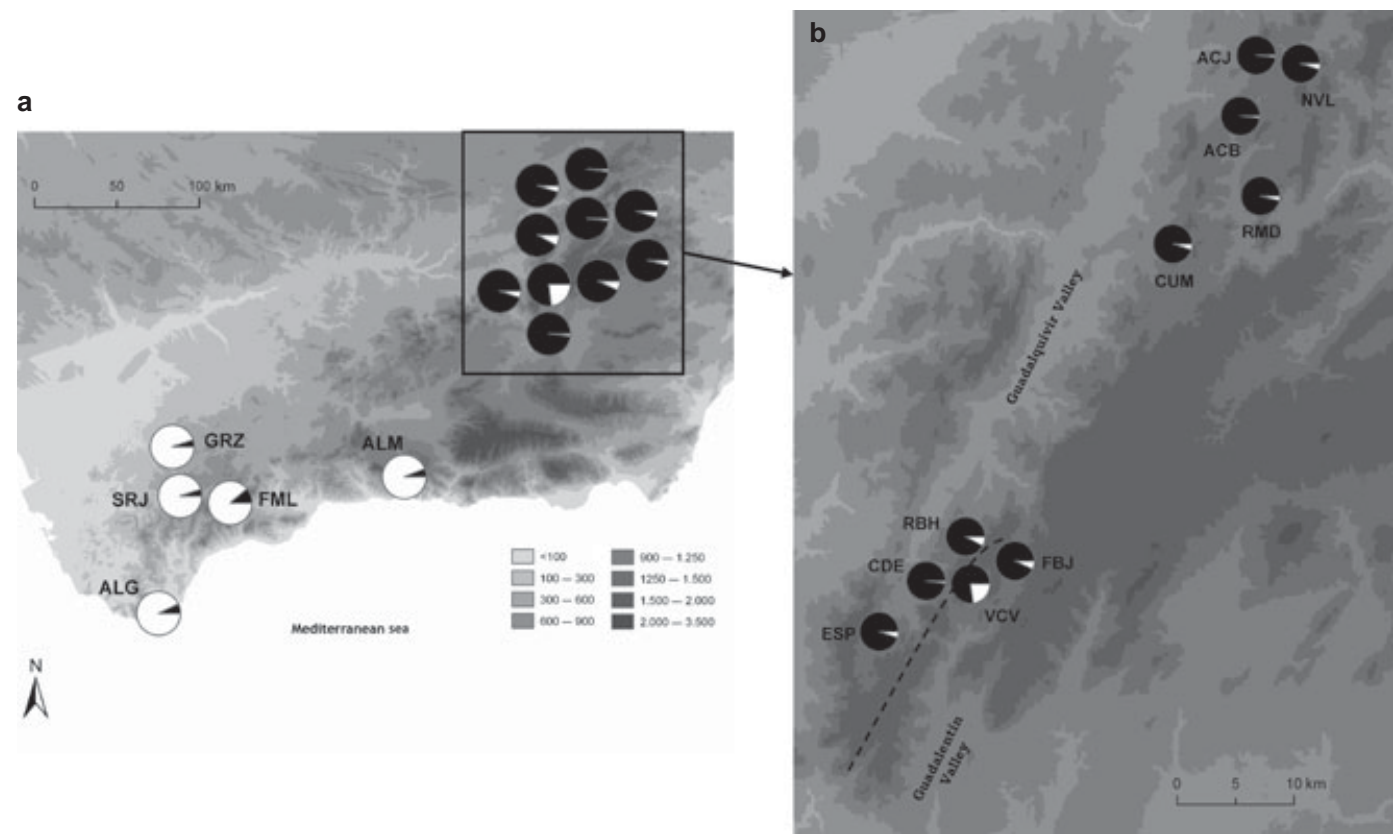

Fig. 4. a: Genetic population structure of Daphne laureola in the Baetic Ranges inferred using model-based Bayesian clustering implemented in stRuctuRE, which does not require a priori categories. The individual pie charts indicate the mean proportion of membership of each local population for the inferred number of $\mathrm{K}=2$ genetic groups. b: Detailed population structure within the largest genetic group that combines core and eastern populations. Dashed line indicates the highest elevation of the mountain range. Populations coded as in Table 2.

these characteristics are expected to vary across species' geographic ranges (Eckert et al. 2008). In the following paragraphs, we discuss our results supporting, first, the increased spatial isolation of marginal populations and, second, the genetic differentiation of the most spatially isolated local margin of the shrub D. laureola in the Mediterranean Baetic Ranges, an area close to the species southern distribution range.

Spatial isolation and size of $\mathrm{D}$. laureola populations in a southern distribution patch

Our results, based on an extensive sampling across the Baetic Ranges, showed that populations of this temperate shrub were fewer and more spatially isolated towards local eastern and western margins, supporting the hypothesis of increased isolation at local range margins (Brown 1984; Vucetich \& Waite 2003; Bridle et al. 2010), and highlighting the suitability of the spatially explicit analysis adopted here to identify meaningful geographic discontinuities (Table 2). The western region comprised a few highly isolated populations located in different mountain ranges (Fig. 1b), the core region with abundant and very connected populations at all distances comprised populations mainly located in the Sierras de Cazorla and Las Villas, and the eastern region was associated with those populations in Sierras de Segura and Alcaraz, where the species is still common but populations exhibit a reduction in connectivity among them (Fig. 1c; Table 2).

The predicted decline in population size towards local borders of distribution was not confirmed in D. laureola populations across the Baetic Ranges (see also Jump \& Woodward 2003; Herlihy \& Eckert 2005). In fact, core populations were on average smaller than marginal populations, although the trend was only significant in the comparison between core and western populations. The wider altitudinal range of core populations could likely contribute to variability in population size in this region through altitudinal gradients in ecological conditions (Herrera \& Bazaga 2008b). The presence of large marginal populations with more than 100 reproductive individuals suggests the existence of some suitable locations without evidence of ecological stress for D. laureola towards the local borders of distribution (Castilla et al. 2011).

Genetic diversity, differentiation and structure, and their relationships with the spatial isolation of populations

Core and marginal populations of D. laureola in the Baetic Ranges exhibited similar levels of genetic diversity, and regions did not differ significantly in either gene diversity or percentage of polymorphic loci within a population. These results contrast with those found for other plants (e.g., Lammi et al. 1999; Lönn \& Prentice 2002; Arnaud-Haond et al. 2006; Eckert et al. 2008). The absence of clear differences between core and marginal populations in genetic diversity could be related to the influence of population size (Lammi et al. 1999; Leimu et al. 2006) because marginal populations, contrary to expectations, were not smaller than core populations. Further, our results supported that PLP was marginally related to population size. Therefore, the existence of large populations on D. laureola's local borders of distribution could prevent genetic erosion through mechanisms of genetic rescue (Young et al. 1996; Garant et al. 2007). Interestingly, the western margin was internally very heterogeneous with regard to genetic diversity of the populations. With the exception of FML population that exhibited the highest genetic diversity among all study populations, the other four tended to have a much more reduced genetic 
diversity than core and eastern populations, mostly supporting the expectation of reduced genetic diversity in the most spatially isolated populations of the western margin, with the single exception already mentioned.

Strong genetic differentiation among D. laureola populations across the Baetic Ranges was indicated in our results using AFLP markers $\left(\mathrm{U}_{\mathrm{ST}}=0.45\right)$. These results are consistent with observed genetic differentiation in DNA sequence in a much-reduced number of sampled populations and individuals (Alonso \& Herrera 2011). In addition, the two estimates of genetic differentiation $\left(\mathrm{F}_{\mathrm{ST}}\right.$ and $\left.\mathrm{DW}\right)$ were positively related to the spatial isolation of populations. In particular, results showed that the highly isolated western populations constitute a genetic group strongly differentiated from core and eastern populations, supporting a positive relationship between geographic isolation and genetic differentiation in our study system (Eckstein et al. 2006; Medrano \& Herrera 2008). Also, our results suggest the existence of two types of local borders of distribution in the study area from a genetic viewpoint: a western margin with populations being both more spatially and genetically isolated among them, as usually happens in the rear edge of species distributions (Hampe \& Petit 2005); and an eastern margin comprising a group of more spatially isolated but genetically homogeneous populations, closely related to core populations and therefore more typical of a expanding edge (Schönswetter et al. 2002; Csergö et al. 2009). The genetic similarity among core and eastern populations suggests extensive gene flow between the two regions. Eastern populations are distant by only about 20 $30 \mathrm{~km}$ from core populations, all located along an extensive mountainous range, which could facilitate local gene flow through natural corridors for the dispersal vectors of the species (see e.g., Gaudeul et al. 2000; Barrett et al. 2004). However, western populations are located far away from the core populations (130 km approximately), limiting the gene flow among western and core populations to long-distance infrequent dispersal events (Kropf et al. 2006, 2008). In addition, western populations are located in different mountain ranges separated by dozens to hundreds of kilometres of unsuitable habitats for the species, which could also reduce gene flow among populations on the western edge, thus promoting their genetic differentiation. Supporting this notion, western populations also had the highest values of genetic rarity estimates, and recent studies have also revealed some ecological particularities of these populations. For instance, the female frequency decreases in southwest populations, the ALG population being constituted exclusively of hermaphrodite plants in the most extreme case (Alonso et al. 2007). In addition, individuals of western populations present lower floral displays than those of core populations, coincident with a change in the pollinator fauna (Castilla et al. 2011). The ecological particularities of western populations and their strong genetic isolation highlight the potential role that local adaptation events could have in these marginal, disjunct populations (Lesica \& Allendorf 1995; García-Ramos \& Kirkpatrick 1997; Arnaud-Haond et al. 2006; Cassel-Lundhagen 2010).

\section{Concluding remarks}

Among-population phenotypic divergence is a relatively common feature in plant species across Mediterranean mountain ranges, geographic margins of species' ranges being particularly prone to the evolution of this random or adaptive differentiation. Background information on patterns of the level of neutral differentiation is particularly interesting for disentangling the role of natural selection on this phenotypic divergence. This approach is especially useful in plant species of Mediterranean mountain ranges because of the strong relevance of historical processes on the genetic structure of their populations. In this sense, genetic structure analyses comparing core and marginal populations based on neutral markers emerge as a useful tool to estimate the level of neutral differentiation in populations where among-population phenotypic differentiation is expected. Results of our study show that neutral differentiation varies on different local margins of distribution. In addition, our results are consistent with historical divergence between western and the remaining populations of D. laureola in the study area, as detected through analysis of markers with a much reduced polymorphism as DNA sequences (Alonso \& Herrera 2011). Therefore, a phenotypic differentiation at the same level in both borders should be evaluated differentially. For instance, if further studies show that eastern populations of D. laureola are phenotypically differentiated from core populations despite their similarity in neutral genetic variation, this phenotypic differentiation could likely represent adaptive differentiation. However, phenotypic differentiation on the western margin should be assessed with more caution because it could be the result of random differentiation via long-term isolation between both groups of populations. Therefore, results of our work highlight the relevance of genetic structure analyses focused on distribution margins as a first step to understanding the adaptive basis of intraspecific differentiation.

\section{ACKNOWLEDGEMENTS}

We thank Alfredo Benavente, Víctor Fernández and the environmental agents of the Andalucian Natural Parks, Angel, Manolo, David and Paco, for their invaluable help in locating the Daphne laureola populations.Thanks to Pilar Bazaga for assistance with AFLP analysis; Thorsten Wiegand for assistance with spatial analysis of the population features; José L. Garrido, Mónica Medrano, Clara de Vega, Francisco Balao and Rafael Albaladejo for comments that improved this manuscript; Peter Schönswetter for advice on estimation of the DW index; and Peter Smouse and Rod Peakall for advice on GenAlEx 6.3. The University of Oslo Bioportal granted access to the TITAN computing cluster. This study was funded by the Spanish Ministerio de Educación y Ciencia through research project CGL 2006-01355/BOS, the Consejo Superior de Investigaciones Científicas (CSIC) through an I3P fellowship to A.R.C. and the project PIE200730/001, and the Consejería de Innovación Ciencia y Empresa, Junta de Andalucía, through research project RNM156-2005.

\section{SUPPORTING INFORMATION}

Additional supporting information may be found in the online version of this article:

Table S1. Primer combinations used, number of markers (loci) obtained in the size range $150-500$ base pairs, observed percentage of polymorphism level (PLP) and error rates in 
the amplified fragment length polymorphism (AFLP) analysis of the 15 Daphne laureola populations studied.

Please note: Wiley-Blackwell are not responsible for the content or functionality of any supporting materials supplied by the authors. Any queries (other than missing material) should be directed to the corresponding author for the article.

\section{REFERENCES}

Alleaume-Benharira M., Pen I.R., Ronce O. (2006) Geographical patterns of adaptation within a species' range: interactions between drift and gene flow. Journal of Evolutionay Biology, 19, 203-215.

Alonso C. (2004) Early blooming's challenges: extended flowering season, diverse pollinator assemblage, and the reproductive success of gynodioecious Daphne laureola. Annals of Botany, 93, 61-66.

Alonso C., Herrera C.M. (2011) Back-and-forth hermaphroditism: phylogenetic context of reproductive system evolution in subdioecious Daphne laureola Evolution, 65, 1680-1692.

Alonso C., Mutikainen P., Herrera C.M. (2007) Ecological context of breeding system variation: sex, size and pollination in a (predominantly) gynodioecious shrub. Annals of Botany, 100, 1547-1556. Applied Biosystems. (2005) AFLP plant mapping protocol. Applied Biosystems, Foster City, CA.

Arnaud-Haond S., Teixeira S., Massa S.I., Billot C., Saenger P., Coupland G., Duarte C.M., Serrão E.A (2006) Genetic structure at range edge: low diversity and high inbreeding in Southeast Asian mangrove (Avicennia marina) populations. Molecular Ecology, 15, 3515-3525.

Barrett S.C.H., Cole W.W., Herrera C.M. (2004) Mating patterns and genetic diversity in the wild Daffodil Narcissus longispathus (Amaryllidaceae). Heredity, 92, 459-465.

Bennett K.D., Tzedakis P.C., Willis K.J. (1991) Quaternary refugia of north European trees. Journal of Biogeography, 18, 103-115.

Birks H.J.B., Willis K.J. (2008) Alpines, trees and refugia in Europe. Plant Ecology \& Diversity, 1, 147-160.

Blondel J., Aronson J., Bodiou J.Y., Boeuf G. (2010) The mediterranean region: biological diversity in space and time, 2nd edition. Oxford University Press, Oxford, UK

Bonin A., Bellemain E., Eidesen P.B., Pompanon F., Brochmann C., Taberlet P. (2004) How to track and assess genotyping errors in population genetics studies. Molecular Ecology, 13, 3261-3273.

Bonin A., Ehrich D., Manel S. (2007) Statistical analysis of amplified fragment length polymorphism data: a toolbox for molecular ecologists and evolutionists. Molecular Ecology, 16, 3737-3758.

Bridle J.R., Vines T. (2007) Limits to evolution at range margins: when and why does adaptation fail? Trends in Ecology and Evolution, 22, 140-147.

Bridle J.R., Polechová J., Kawata M., Butlin R.K. (2010) Why is adaptation prevented at ecological margins? New insights from individual-based simulations. Ecology Letters, 13, 485-494.

Brown J.H. (1984) On the relationship between abundance and distribution of species. American Naturalist, 124, 255-279.

Brussard P.F. (1984) Geographic patterns and environmental gradients: the central-marginal model in Drosophila revisited. Annual Review of Ecology and Systematics, 15, 25-64.
Caballero A., Quesada H., Rolán-Alvarez E. (2008) Impact of Amplified Fragment Length Polymorphism size homoplasy on the estimation of population genetic diversity and the detection of selective loci. Genetics, 179, 539-544.

Carrión J.S. (2002) Patterns and processes of Late Quaternary environmental change in a montane region of southwestern Europe. Quaternary Science Reviews, 21, 2047-2066.

Carrión J.S., Yll E.I., Walker M.J., Legaz A.J., Chaín C., López A. (2003) Glacial refugia of temperate, Mediterranean and Ibero-North African flora in south-eastern Spain: new evidence from cave pollen at two Neanderthal man sites. Global Ecology and Biogeography, 12, 119-129.

Cassel-Lundhagen A. (2010) Peripheral relict populations of widespread species; evolutionary hotspots or just more of the same? In: Habel J.C., Assmann T. (Eds), Relict species: phylogeography and conservation biology. Springer-Verlag, Berlin, Heidelberg, pp 267-275.

Castilla A.R., Alonso C., Herrera C.M. (2011) Exploring local borders of distribution in the shrub Daphne laureola: individual and population traits. Acta Oecologica, 37(3), 269-276.

Csergö A.M., Schönswetter P., Mara G., Deák T., Boscaiu N., Höhn M. (2009) Genetic structure of peripheral, island-like populations: a case study of Saponaria bellidifolia Sm. (Caryophyllaceae) from the Southeastern Carpathians. Plant Systematics and Evolution, 278, 33-41.

Eckert C.G., Samis K.E., Lougheed S.C. (2008) Genetic variation across species' geographical ranges: the central-marginal hypothesis and beyond. Molecular Ecology, 17, 1170-1188.

Eckstein R.L., O’Neill R.A., Danihelka J., Otte A., Köhler W. (2006) Genetic structure among and within peripheral and central populations of three endangered floodplain violets. Molecular Ecology, $15,2367-2379$.

Ehrich D. (2006) AFLPdat: a collection of R functions for convenient handling of AFLP data. Molecular Ecology Notes, 6, 603-604.

Evanno G., Regnaut S., Goudet J. (2005) Detecting the number of clusters of individuals using the software STRUCTURE: a simulation study. Molecular Ecology, 14, 2611-2620.

Excoffier L., Smouse P.E., Quattro J.M. (1992) Analysis of molecular variance inferred from metric distances among DNA haplotypes: application to human mitochondrial DNA restriction data. Genetics, 131, 479-491.

Falush D., Stephens M., Pritchard J.K. (2007) Inference of population structure using multilocus genotype data: dominant markers and null alleles. Molecular Ecology Notes, 7, 574-578.

Felsenstein J. (1985) Confidence limits on phylogenies: an approach using the bootstrap. Evolution, 39, 783-791.

Garant D., Forde S.E., Hendry A.P. (2007) The multifarious effects of dispersal and gene flow on contemporary adaptation. Functional Ecology, 21, 434-443.
García-Ramos G., Kirkpatrick M. (1997) Genetic models of adaptation and gene flow in peripheral populations. Evolution, 51, 21-28.

Gaudeul M., Taberlet P., Till-Bottraud I. (2000) Genetic diversity in an endangered alpine plant, Eryngium alpinum L. (Apiaceae), inferred from amplified fragment length polymorphism markers. Molecular Ecology, 9, 1625-1637.

Hampe A., Petit R.J. (2005) Conserving biodiversity under climate change: the rear edge matters. Ecology Letters, 8, 461-467.

Hengeveld R., Haeck J. (1982) The distribution of the abundance I. Measurements. Journal of Biogeography, 9, 303-316.

Herlihy C.R., Eckert C.G. (2005) Evolution of self-fertilization at geographical range margins? A comparison of demographic, floral, and mating system variables in central vs. peripheral of Aquilegia canadensis (Ranunculaceae). American Journal of Botany, 92, 744-751.

Herrera C.M., Bazaga P. (2008a) Adding a third dimension to the edge of a species' range: altitude and genetic structuring in mountainous landscapes. Heredity, 100, 275-285.

Herrera C.M., Bazaga P. (2008b) Population-genomic approach reveals adaptive floral divergence in discrete populations of a hawk moth-pollinated violet. Molecular Ecology, 17, 5378-5390.

Hulme P.E. (1992) The ecology of a temperate plant in a Mediterranean environment: post-dispersal seed predation of Daphne laureola. In: Thanos C.A. (Ed), Plant-animal interactions in Mediterraneantype ecosystems. University of Athens, Athens, Greece, pp 281-286.

Illian J., Penttinen A., Stoyan H., Stoyan D. (2008) Statistical analysis and modelling of spatial point patterns. John Wiley \& Sons, Chichester, UK.

Jump A.S., Woodward F.I. (2003) Seed production and population density decline approaching the range-edge of Cirsium species. New Phytologist, 160, 349-358.

Kropf M., Comes H.P., Kadereit J.W. (2006) Longdistance dispersal vs. vicariance: the origin and genetic diversity of alpine plants in the Spanish Sierra Nevada. New Phytologist, 172, 169-184.

Kropf M., Come H.P., Kadereit J.W. (2008) Causes of the genetic architecture of south-west European high mountain disjuncts. Plant Ecology and Diversity, 1, 217-228.

Lammi A., Siikamäki P., Mustajärvi K. (1999) Genetic diversity, population size, and fitness in central and peripheral populations of a rare plant Lychnis viscaria. Conservation Biology, 13, 1069-1078.

Leimu R., Mutikainen P., Koricheva J., Fischer M. (2006) How general are positive relationships between plant population size, fitness and genetic variation? Journal of Ecology, 94, 942-952.

Lesica P., Allendorf F.W. (1995) When are peripheral populations valuable for conservation? Conservation Biology, 9, 753-760.

Lönn M., Prentice H.C. (2002) Gene diversity and demographic turnover in central and peripheral populations of the perennial herb Gypsophila fastigiata. Oikos, 99, 489-498. 
Lowe A.J., Boshier D., Ward M., Bacles C.F.E., Navarro C. (2005) Genetic resource impacts of habitat loss and degradation: reconciling empirical evidence and predicted theory for neotropical trees. Heredity, 95, 255-273.

Médail F., Diadema K. (2009) Glacial refugia influence plant diversity patterns in the Mediterranean Basin. Journal of Biogeography, 36, 1333-1345.

Medina R.F., Barbosa P., Christman M., Battisti A. (2006) Number of individuals and molecular markers to use in genetic differentiation studies. Molecular Ecology Notes, 6, 1010-1013.

Medrano M., Herrera C.M. (2008) Geographical structuring of genetic diversity across the whole distribution range of Narcissus longispathus, a habitat-specialist, Mediterranean narrow endemic. Annals of Botany, 102, 183-194.

Meusel H., Jäger E., Rauschert S., Weinert E. (1978) Vergleichende Chorologie der zentraleuropäischen Flora, Band III. Gustav Fischer, Jena.

Obeso J.R. (1985) Comunidades de pájaros y frugivorismo en altitudes medias de la Sierra de Cazorla. Ph.D. thesis. University of Oviedo, Oviedo, Spain.
Peakall R., Smouse P.E. (2006) GENEALEX 6: genetic analysis in Excel. Population genetic software for teaching and research. Molecular Ecology Notes, 6, 288-295. Available from http://www.anu.edu.au/ BoZo/GenAlEx.

Pompanon F., Bonin A., Bellemain E., Taberlet P. (2005) Genotyping errors: causes, consequences and solutions. Nature Reviews Genetics, 6, 847-859.

Pritchard J.K., Stephens M., Donnelly P. (2000) Inference of population structure using multilocus genotype data. Genetics, 155, 945-959.

Ripley B.D. (1981) Spatial statistics. Wiley, New York. SAS Institute (2002) SAS for windows (version 9.13). SAS Institute: Cary, NC, USA.

Schönswetter P., Tribsch A. (2005) Vicariance and dispersal in the alpine perennial Bupleurum stellatum L. (Apiaceae). Taxon, 54, 725-732.

Schönswetter P., Tribsch A., Barfuss M., Niklfeld H. (2002) Several Pleistocene refugia detected in the high alpine plant Phyteuma globulariifolium Sternb. \& Hoppe (Campanulaceae) in the European Alps. Molecular Ecology, 11, 2637-2647.
Thompson J.D. (2005) Plant evolution in the mediterranean, 1st edition. Oxford University Press, Oxford, UK.

Vekemans X., Beauwens T., Lemaire M., Roldán-Ruiz I. (2002) Data from amplified fragment length polymorphism (AFLP) markers show indication of size homoplasy and of a relationship between degree of homoplasy and fragment size. Molecular Ecology, 11, 139-151.

Vos P., Hogers R., Bleeker M., Reijans M., van de Lee T., Hornes M., Frijters A., Pot J., Peleman J., Kuiper M., Zabeau M. (1995) AFLP: a new technique for DNA fingerprinting. Nucleic Acids Research, 23, 4407-4414.

Vucetich J.A., Waite T.A. (2003) Spatial patterns of demography and genetic processes across the species' range: null hypotheses for landscape conservation genetics. Conservation Genetics, 4, 639-645.

Young A., Boyle T., Brown T. (1996) The population genetic consequences of habitat fragmentation for plants. Trends in Ecology and Evolution, 11, 413418. 